\section{EFFECT OF HOME VISIT ON MORTALITY AND MORBIDITY OF PRETERM NEWBORN}

doi:10.1136/archdischild-2012-302724.1849

M Edraki, H Morravej, M Rambod, M Soltanian. Shiraz University of Medical Sciences, Shiraz, Iran

Introduction Some studies have indicated that home-based newborn visit interventions can prevent of newborn deaths The aim of this study was to determine the effectiveness of home visit on mortality and morbidity of Preterm newborn.

Method This is a semi-experimental study in which Preterm newborn with fetal age of less than 37 weeks weighing below 2500 grams were placed in two groups of case (30 neonates) and control (30 neonates) randomly. Home visit was presented to case group for a period of 6 months after discharging from hospital. Control group received hospital routine cares and referred for visiting. Both groups were followed up for a period of 6 months. The samples of both groups were compared with each other from the view point of mortality and hospitalization. Collected data were analyzed using $\mathrm{X}^{2}$ and independent $\mathrm{T}$ test.

Results The mortality during first six months of life of both groups did not show any difference ( $P>0.05)$. However, the number of inpatient cases of neonates and also the number of their disease cases not required to be hospitalized during first six months of life among case group was less than that of control group $(\mathrm{P}<0.05)$.

Conclusion The results of this study indicated that, carrying out home visit by health care givers results in reducing the number of inpatient cases of neonates during first six months of life. Therefore, it is suggested to appoint home visit as a part of health programs so as to reduce neonates' hospitalization cases and thereby to improve their health.

\section{THE MEANING OF PERSONAL DIARIES IN PICU TO CHILDREN AND FAMILIES}

doi:10.1136/archdischild-2012-302724.1850

G Mikkelsen, D Gundberg. Pediatric Intensive Care Unit BRITA, Odense University Hospital, Odense, Denmark

Background and Aims In our PICU, nurses have for several years been writing a personal diary for all children admitted for 3 days or more. The purpose of the diary is to help the children understand their recollections and experiences from the PICU stay and thereby support their coping.

Research involving adult ICU patients has explored patients experiences with diaries and the effect on psychological outcome, but no PICU studies have been reported on the subject.

Thus the aim of our study was to investigate how diaries are being used and to explore their role in coming to term with the PICU stay.

Methods 5 semi-structured interviews with children and their families, 4-6 months after discharge from PICU. The data was analyzed using the method of systematic textcondensation described by Kirsti Malterud. During this analytic process the text is decontextualised into "units of meaning" from which themes and subthemes are identified.

Results One family had not used the diary much and ascribed this to a short PICU stay. The remaining families all expressed positive opinions of the diary and saw it as one of several tools to help understand and make sense of their experiences from PICU.

Three main themes emerged from the analysis:

Value to the entire family.

Creating memories.

The importance of pictures.

Conclusions Personal diaries are used in the families after discharge as support for both children and their relatives. They play an important role in making the PICU experience meaningful by providing explanations and coherence.
FAMILY LIFE AND PARENTHOOD AFTER BIRTH OF LATE PRETERM INFANT

doi:10.1136/archdischild-2012-302724.1851

H Haslund. NICU, Aalborg Sygehus, Aarhus University Anthropology Department, Aalborg, Denmark

Background and Aim Danish studies show that prematuremothers develop PTSD symptoms more frequent than the rest of the population. Little research has been conducted on familiy life the first year after birth of a late preterm infant (GW 32-37) and they are discharged to normalcy without extra health care sevices. Methods A Phd in anthropology is research frame. My one and a half year fieldwork in danish families after birth of a late preterm child consists of participant observation in every day life and interviews. Health care nurse visits are included as well as peer groups of mothers.

Results My preliminary findings show a heavy focus on monitorring child development and health being associated with good parenting. Parenthood is a professionalized and highly moral practice. In spite of an eccesive amount of knowledge on babycare parents experience much uncertainty in the multiple daily choises on sleep, stimulation, contact, food etc. The premature birth as event with hospitalisation and an experience of risk, accentuates the insecurity as it is difficult to make sure wheather or not the child is to be cosidered normal. Peer Groups of mothers are thought to be a place of recognition and sharing, but can negatively cotribute to the stigma of premature families in the process of mutual assesment that is practiced in the groups.

Conclusion The development and health oriented focus in Denmark 2012 has generated a monitoring practice that contributes to parental insecurity and a sense of difference in stead of being empowered.

\section{EFFECT OF CONFLICT RESOLUTION TRAINING ON BEHAVIORAL PROBLEMS IN CHILDREN IN COUPLES REFERRING TO COUNSELING CENTERS IN SHIRAZ-IRAN, 2011}

doi:10.1136/archdischild-2012-302724.1852

'F Sharif, ${ }^{2} \mathrm{~S}$ Solymani, ${ }^{3} \mathrm{~A}$ Mani, ${ }^{4} \mathrm{~S}$ Keshavarzi. ${ }^{1}$ Psychiatric \& Mental Health Nursing, Community Based Nursing \& Midwifery Research Center; ${ }^{2}$ Psychiatric \& Mental Health Nursing; ${ }^{3}$ Psychiatry; "Biostatistic, Shiraz University of Medical Sciences, Shiraz, Iran

Background and Aim Marital conflicts are among the most common problems in today's society. The impacts of marital conflicts on the children's behavioral problems have also been approved. We aimed to examine the effects of conflict resolution training on the children's behavioral problems in a sample of Iranian couples.

Methods This study performed on 56 couples who had the required criteria \& were randomly selected. These couples had moderate to severe conflict scores (60 and over) based on the marital conflict questionnaire. The subjects were divided into two groups, using blocking random allocation. Then the experimental group was randomly subdivided into three groups and received 10 sessions conflict resolution skills training. The level of conflict and child behavioral problems was checked before, immediately, and one month after intervention in the experimental groups. In the control group these amounts were checked before and one month after intervention.

Results In this study both groups were homogenous demographically with no statistically significant differences. Mean score of marital conflict before, immediately, and one month after intervention was statistically significant in men and women $(\mathrm{P}<0.0001)$; But not in control group. Mean score of child behavioral problems before, immediately, and one month after intervention was not statistically significant in both groups.

Conclusion Conflict resolution training was effective in reducing marital conflicts. Therefore this method can be recommended for couples. 